\title{
REVIEW
}

\section{Prolactin receptor signal transduction in cells of the immune system}

\author{
C V Clevenger, D O Freier and J B Kline \\ Department of Pathology and Laboratory Medicine, University of Pennsylvania Medical Center, Philadelphia, Pennsylvania 19104, USA \\ (Requests for offprints should be addressed to C V Clevenger, Department of Pathology and Laboratory Medicine, University of Pennsylvania Medical Center, \\ 509 Stellar-Chance Laboratories, 422 Curie Boulevard, Philadelphia, Pennsylvania 19104, USA)
}

\section{Introduction}

Prolactin (PRL) was originally identified as a neuroendocrine hormone of pituitary origin (Riddle \& Braucher 1931, Riddle et al. 1933). While the primary function of this hormone was initially thought to lie solely within the breast, the functional pleiotropism of this peptide with regards to reproduction, osmoregulation, and behavior was subsequently recognized (Nicoll 1974). Several lines of evidence have now also demonstrated an immunoregulatory role for this peptide. Structural analysis of PRL has revealed it to be related to members of the cytokine/ hematopoietin family such as growth hormone $(\mathrm{GH})$, erythropoietin, granulocyte-macrophage colony stimulating factor (GM-CSF) and the interleukins (IL) IL-2 to IL-7 (Bazan 1990). Synthesis of PRL is not limited to the hypophysis, as numerous extra-pituitary sites of PRL expression including the decidua, breast, and $\mathrm{T}$ lymphocytes have been detected (DiMattia et al. 1986, Montogomery et al. 1987, Clevenger et al. 1990, Gellersen et al. 1994, Ginsburg \& Vonderhaar 1995, Mershon et al. 1995, Clevenger \& Plank 1997). The receptor for PRL (PRLr) is present on $\mathrm{T}$ and $\mathrm{B}$ lymphocytes and macrophages (Pellegrini et al. 1992, Dardenne et al. 1994). Acting through its receptor, PRL modulates immune system function by stimulating both cell proliferation and survival. Taken together, these data indicate that PRL acts at the endocrine, paracrine, and autocrine levels in regulating immune function (Gala 1991, Prystowsky \& Clevenger 1994, Kooijman et al. 1996, Yu-Lee 1997). This review initially focuses on the immunoregulatory functions of PRL in the immune system, and then focuses on the structure/ function relationships within the PRLr as they pertain to immunologically relevant signal transduction pathways.

\section{Function of PRL as a cytokine within the immune system}

\section{Role as a mitogen}

The antigen-driven clonal expansion of $\mathrm{T}$ lymphocytes is an essential component of an effective immune response. Similar to other ILs, PRL acts as a necessary co-mitogen during lymphoid expansion. An immunomodulatory role for PRL was first identified in avian and murine species, secondary to in vivo manipulation of serum PRL levels (Berczi et al. 1981, Nagy et al. 1983, Glick 1984, Nagy \& Berczi 1991). Subsequent in vitro studies have found that in the presence of antigen and/or mitogen, PRL acts as a necessary co-mitogen for $\mathrm{T}$ and $\mathrm{B}$ cells of human or murine origin (Russell et al. 1984, Bernton et al. 1988, Hartmann et al. 1989, Clevenger et al. 1990, Skwarlo-Sonta 1990). PRL may also serve as an in vitro co-mitogen for NK (natural killer) cells and macrophages (Bernton et al. 1988, Matera et al. 1992). Via its receptor present on these cell types, PRL regulates lymphocyte proliferation by modulating the expression of gene products necessary for cell cycle progression (Yu-Lee 1990, Clevenger et al. 1992).

Manipulation of PRL levels in rodent models, followed by immunologic challenge (i.e. antigen or infection) has provided an additional in vivo confirmation of the immunostimulatory role for PRL. Reconstitution of an appropriate immune response following challenge with either sheep red blood cells or Escherichia coli lipopolysaccharide was achieved in hypophysectomized, immunocompromised rats following administration of $40 \mu \mathrm{g}$ PRL/rat per day (Berczi et al. 1981). Use of other pituitary hormones, or combinations thereof including $\mathrm{GH}$, failed to restore the immunologic response of these animals. Mice treated with $2 \mathrm{mg}$ PRL/kg per $12 \mathrm{~h}$ and subsequently exposed to Salmonella typhimurium demonstrated a $66 \%$ reduction in mortality (Di Carlo et al. 1993). The infusion of PRL also mediated a dramatic improvement in the survival of bromocriptine-treated mice after intraperitoneal injection of Listeria monocytogenes (Bernton et al. 1988). This effect was possibly due to a concomitant regulation by PRL of $\gamma$-interferon production by $\mathrm{T}$ lymphocytes. Finally, the conjoint treatment of intact mice with PRL and $\gamma$-interferon resulted in a $75 \%$ survival rate following a lethal dose of Toxoplasma gondii (Benedetto et al. 1995). In humans, decreases in PRL levels mediated by the administration of dopamine induced a transient, but significant, reduction in the overall responsiveness of isolated peripheral blood lymphocytes to mitogens (Devins et al. 1992, Bailey \& Burchett 1997). 


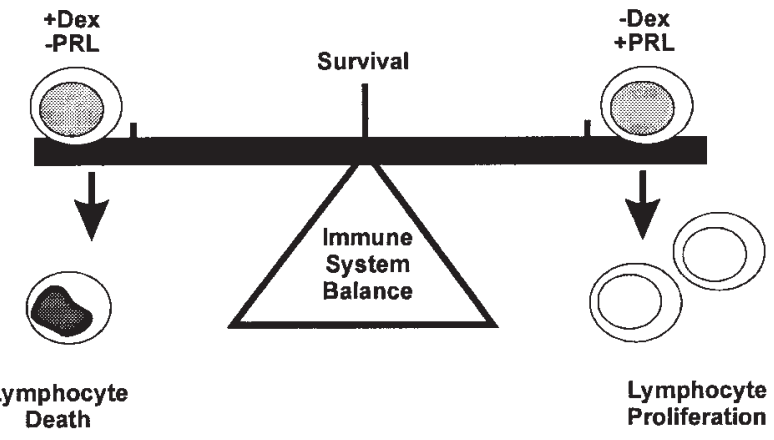

Figure 1 Immunologic homeostasis is a balance between the counteracting effects of PRL and glucocorticoids of lymphocyte progenitors. While glucocorticoids inhibit lymphocyte proliferation and trigger apoptosis, PRL stimulates proliferation and enhances cell survival. Concomitant addition of these hormones to lymphocytes in vitro induces a stasis with regards to viable cell numbers.

\section{Role as a survival factor}

During periods of stress, increased levels of PRL are released from the pituitary, approximately paralleling the secretion of corticotropin releasing factor (Kant et al. 1992). While necessary for the maintenance of overall metabolism and survival during periods of stress, one potentially undesirable effect of glucocorticoids is their inhibition of immune responses. While this inhibition occurs by many mechanisms, one of the principal causes of glucocorticoid-induced immunosuppression is its induction of apoptosis in $\mathrm{T}$ cell progenitor populations (Wyllie 1980, Evans-Storms \& Cidlowski 1995). As described above, acute decreases in PRL levels in both rodent models and humans result in decreased immunoeffectiveness. A physiologic linkage between the immunosuppression induced by glucocorticoid excess or PRL deficiency has been recently obtained. While examining the effects of glucocorticoids on the PRL-dependent $\mathrm{T}$-cell line $\mathrm{Nb} 2$, Witorsch and colleagues found that either pretreatment or concomitant treatment of $\mathrm{Nb} 2$ cells with PRL significantly inhibited glucocorticoid-induced apoptosis (Fletcher-Chiappini et al. 1993, Witorsch et al. 1993). While treatment with glucocorticoid led to a $10-$ fold reduction in viable cell number, concomitant treatment of $\mathrm{Nb} 2$ cultures with both PRL and glucocorticoid induced a relative stasis in the total number of viable cells. These studies also demonstrated that PRL in defined culture could inhibit the dexamethasone (Dex)induced apoptosis of normal murine thymocytes. Thus, at the neuro-immune level, PRL and glucocorticoids appear to antagonize their respective actions, resulting in the appropriate titration of immune response (see Fig. 1).

\section{Expression of PRL within the immune system}

The observation of a PRL-like immunoreactivity in the medium of cultured lymphoblastoid cell lines initially triggered the speculation that lymphocytes could express PRL (DiMattia et al. 1986, Montogomery et al. 1987, Kenner et al. 1991). The function of this autocrine/ paracrine PRL was subsequently demonstrated by the growth inhibitory effects of anti-PRL antiserum on mitogen-stimulated lymphocytes (Bernton et al. 1988, Hartmann et al. 1989, Clevenger et al. 1990). At the level of RNA, PRL expression is found only in T lymphocytes (Pellegrini et al. 1992). Molecular analysis of the promoter regions utilized in the synthesis of PRL has revealed that both the proximal and distal promoters of this gene locus are utilized in T cells (Gellersen et al. 1994). In the absence of expression of the transcription factor Pit-1, however, function of only the distal promoter was observed. Analysis of this distal PRL promoter region has revealed a lymphoid-specific enhancer element between -212 and - 375 bp upstream from the transcription start site which demonstrated two protected regions when analyzed by footprint analysis using Jurkat $\mathrm{T}$-cell lysates (Berwaer et al. 1994). Further study of the distal PRL promoter has indicated a role for CAMP, acting through protein kinase A and cAMP response element, and other as yet unidentified factors in the control of this transcriptional regulatory unit (Gellersen et al. 1995, Telgmann et al. 1997).

In vivo analysis of $P R L$ function through targeted genetic disruption

An additional tool in the in vivo analysis of PRL function has been recently gained by the development of mice with targeted gene disruptions ('knock-outs') of both the PRL (Horseman et al. 1997) and PRLr (Ormandy et al. 1997) loci. While examination of both knock-out progeny has revealed deficits in terminal mammary differentiation and fertility, no obvious defect in hematopoiesis or lymphopoiesis was observed. Flow cytometric analysis of the peripheral blood, spleen, thymus, and lymph nodes revealed normal numbers of both $\mathrm{T}$ and $\mathrm{B}$ cells in the PRL knock-out mouse. These data clearly indicate that PRL alone is not required for the development of normal numbers of immune system cells. Presumably other compensatory mechanisms, specifically the actions of other members of the cytokine family, enable normal lymphopoiesis. Significantly, the normal and stressed functions of the immune systems of either knock-out mouse have not been reported at the time of this review. Such studies may provide both confirmatory and novel insights into the role of PRL during an immune response.

\section{Mediation of PRL function by PRLr structure}

The expression of the PRLr on macrophages, and $\mathrm{T}$ and $\mathrm{B}$ cells has been confirmed at the protein and RNA levels (Clevenger et al. 1990, Pellegrini et al. 1992). Increases in the levels of PRLr expression can be effected by either 


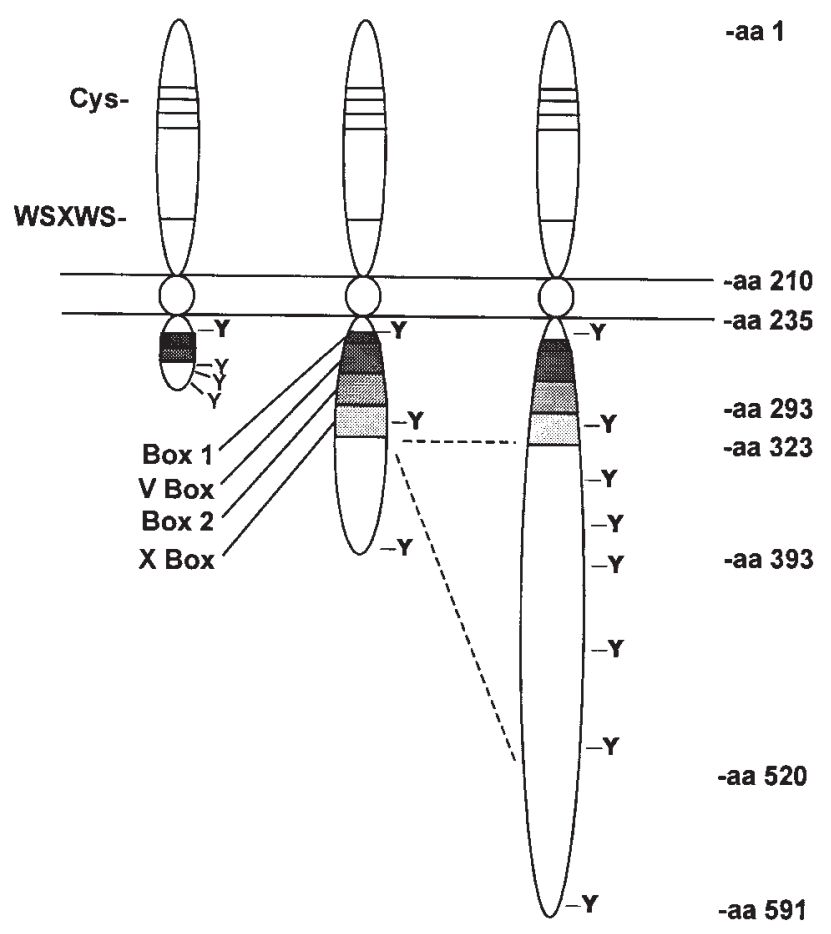

\section{PRLr Isoforms: Short Intermediate Long}

Figure 2 Structure of the three known rat PRLr isoforms. The short and the long isoforms result from differential splicing, while the intermediate form represents a deletion mutant of the long isoform found in the PRL-dependent, T- cell lymphoma line Nb2. In humans, expression of the intermediate form results from differential splicing. Tyrosine residues are designated by ' $\mathrm{Y}$ ', cysteine residues by 'Cys' and the tryptophan-serine-X-tryptophan-serine motif is marked by 'WSXWS'. A description of the intracellular motifs can be found in the text.

mitogen or cytokine stimulation (Clevenger et al. 1990, Dardenne et al. 1994). Confirmation that the PRLr mediates the effects of PRL has been demonstrated by the mitogenic properties of a cross-linking anti-PRLr antibody on the Nb2 T- cell line (Elberg et al. 1990). Three isoforms of PRLr have been cloned in the rat (see Fig. 2): the 'short' (PRLr-S, approximately 291 amino acids, approximately $45 \mathrm{kDa}$ ), 'long' (PRLr-L, approximately 592-598 amino acids, 80-85 kDa), and intermediate (PRLr-I, a deletion mutant missing amino acids 323-520 of the PRLr-L isoform, found in the PRL-dependent rat T-cell lymphoma line Nb2; 393 amino acids, approximately $65 \mathrm{kDa}$ ) (Boutin et al. 1988, 1989, Ali et al. 1991). In humans, two PRLr isoforms have been identified: the long (Boutin et al. 1989) and a novel intermediate isoform, recently identified in our laboratory (Clevenger et al. 1995a). All PRLr isoforms are homologous in their extracellular and transmembrane domain; alternative mRNA splicing accounts for the differing sizes of the cytoplasmic domain, with the exception of the $\mathrm{Nb} 2$ mutant form, which is believed to result from a mutation in the exon encoding for rat PRLr intracellular domain (Ali et al. 1991). The extracellular domain of the PRLr demonstrates homology via a tryptophan-serine box motif with the gene superfamily of cytokine receptors that includes the receptors for IL-2 to IL-7, GM-CSF, GH, and erythropoietin (Bazan 1989).

Structure/function analysis of the intracellular/signaling domain of the PRLr has indicated that four conserved structural motifs, present in the superfamily of cytokine receptors, namely the box 1 , variable box ('V box'), box 2 and extended box 2 ('X box') are present in this receptor (Ihle \& Kerr 1995). The box 1 motif consists of a hydrophobic proline-rich region and presents some similarity with the Src homology 3 (SH3) binding sites. The box 2 motif, present in PRLr-I and PRLr-L but absent in PRLr-S, is rich in hydrophobic and acidic amino acid residues. The intervening region between box 1 and box 2 is the V box; only a partial sequence of this motif is found within the PRLr-S. On the carboxy side of the box 
Maximal Proliferation

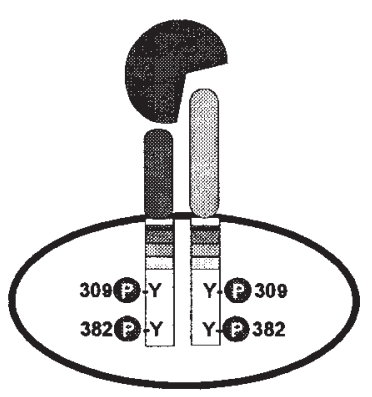

Partial Proliferation
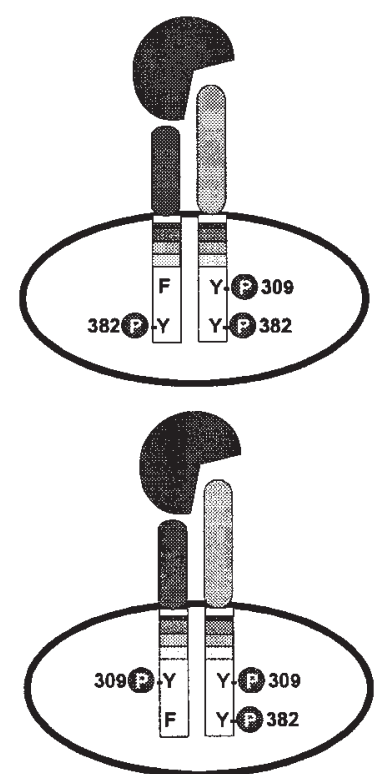

No Proliferation

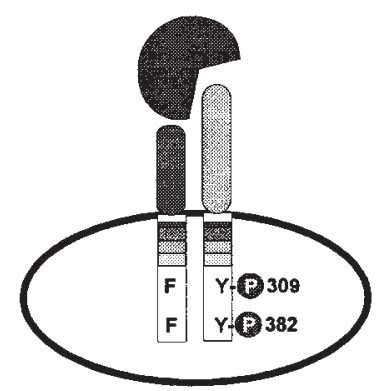

Figure 3 Effect of stoichiometric replacement of tyrosine residues within the carboxy terminus of the PRLr. Two pairs of tyrosine residues reside in the carboxy terminus of the functional intermediate isoform of the PRLr and were thought to contribute to PRLr-associated signaling and proliferation. To test the functionality and stoichiometry of these residues, chimera of the extracellular domains of the GM-CSFr and the intracellular of the intermediate PRLr isoform were utilized. Replacement of any one tyrosine residue reduced both PRLr-associated signaling and proliferation by $60-70 \%$, while replacement of one tyrosine residue in each chain ('in trans') reduced PRLr function by $90 \%$. In contrast, replacement of two tyrosine residues on one intracellular chain ('in cis') led to a complete ablation of signaling and proliferation. These data support the hypothesis that PRLr tyrosine transphosphorylation serves as an important proximal signaling mechanism for this receptor complex.

2 motif resides the $\mathrm{X}$ box, a region poorly conserved between the cytokine receptors, required for the function of some members of the cytokine receptor family (Miura et al. 1993). Functional analysis of the different PRLr isoforms in a transient promoter/reporter assay system has found that both the PRLr-L and the PRLr-I, but not the PRLr-S, can initiate transcription from a PRL-responsive promoter (Lesueur et al. 1991, Ali et al. 1992, O’Neal \& Yu-Lee 1994). When stably transfected into the cytokine responsive line $\mathrm{Ba} / \mathrm{F} 3$, the PRLr-L and PRLr-I isoforms were comparable at stimulating PRL-driven cell proliferation and gene expression (O’Neal \& Yu-Lee 1994), while the PRLr-S isoform lacked such activity.

As no PRL-responsive tissue has been shown to express only a single PRLr isoform (Nagano \& Kelly 1994), the formation of heterodimeric complexes within cells of the immune system may be more of a rule than an exception. To test the functional significance of PRLr isoform heterodimerization, chimeric receptor constructs were recently utilized by our laboratory (Chang \& Clevenger 1996). These chimeric receptors contained the extracellular domains of the human GM-CSFr $\alpha$ or $\beta$ subunit, termed $\alpha$ or $\beta$ respectively, and the transmembrane and intracellular domains of the rat PRLr-I and PRLr-S isoforms. When these chimeras (termed $\alpha \mathrm{S}, \alpha \mathrm{I}, \beta \mathrm{S}$, or $\beta \mathrm{I}$ ) were co-expressed in the IL-3-dependent B lymphocyte $\mathrm{Ba} / \mathrm{F} 3$ line, ligand-induced dimerization of the extracellular domains induced a specific one-to-one pairing of the PRLr intracellular domains. While transfectants expressing the $\alpha \mathrm{I} / \beta \mathrm{I}$ homodimer demonstrated ligandinduced function equivalent to the wild-type PRLr, expression of either homo- or heterodimers of the PRLr-S isoform $(\alpha \mathrm{S} / \beta \mathrm{S}, \alpha \mathrm{S} / \beta \mathrm{I}$, or $\alpha \mathrm{I} / \beta \mathrm{S})$ acted in a dominant negative manner inhibiting both ligand-driven proliferation and receptor-associated signaling. Thus, these results demonstrated that functional pairing of structures other than the box 1 motif, such as the V box, box 2, X box, and the carboxy tail of the PRLr, are required for mitogenesis and activation of Jak2 and Fyn. We have extended these studies to examine the structural stoichiometry of the PRLr complex (Chang et al. 1998). Specifically, the numerical contributions of the membrane-proximal region of the intracellular domain (i.e. box $1 / \mathrm{V}$ box/box 2/X box motifs) and the carboxy-terminal tyrosines to PRLr function were tested. Regardless of the number of $\mathrm{V}$ box or box 2 motifs present in the ligand-induced 


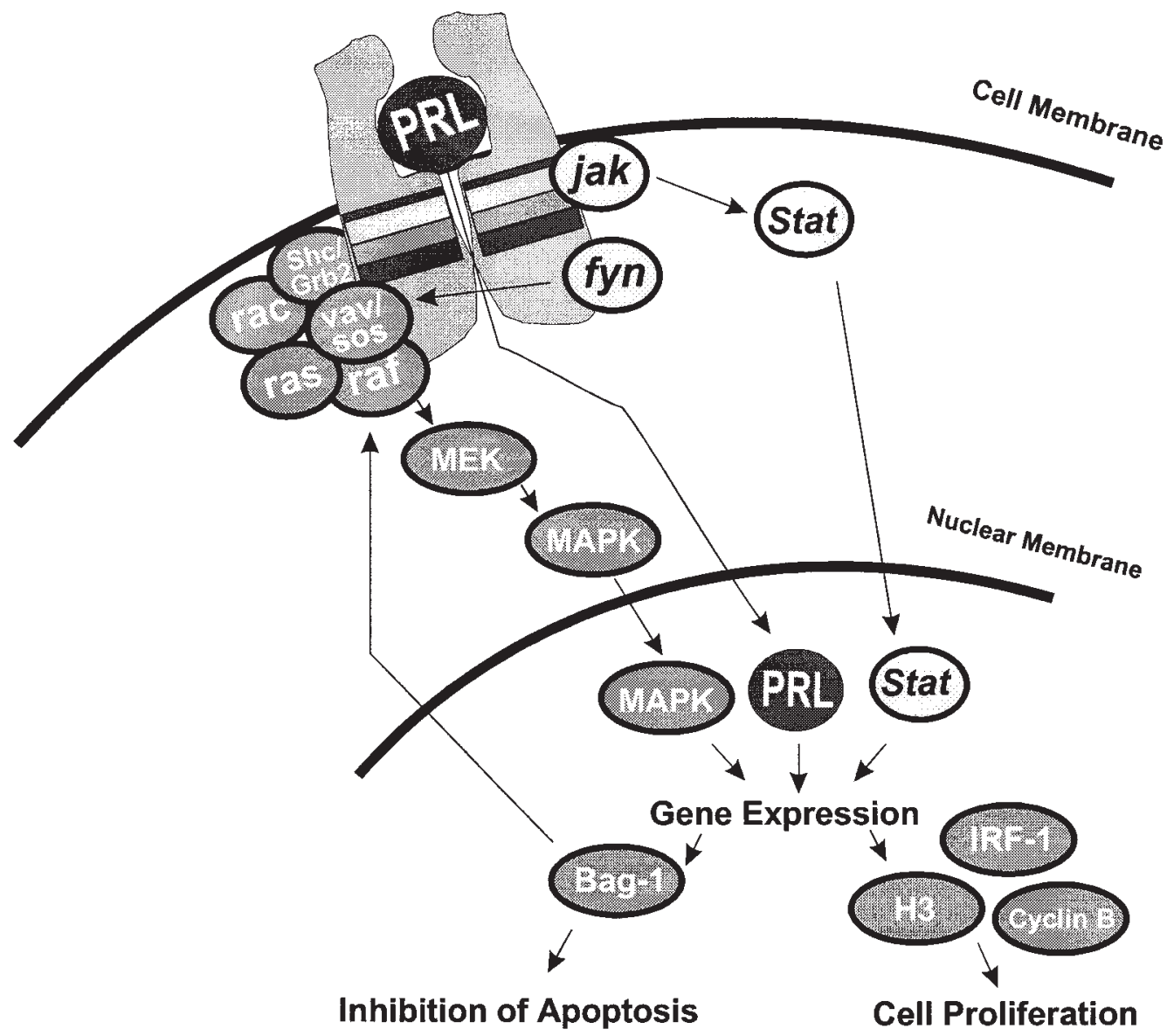

Figure 4 PRLr signal transduction activates multiple signaling pathways. Ligand-induced activation of the PRLr complex has been found to activate the JAK/Stat, Shc-MAPK, and Fyn pathways. Cross-talk between these pathways appears to be more the rule, than the exception. PRL has been noted to translocate into the nucleus of IL-2-stimulated lymphocytes and also appears necessary for PRL-driven proliferation (Clevenger et al. 1991). Ongoing work seeks to characterize the mechanism of ligand internalization and intranuclear function.

chimeric receptor complexes, the absence of one of the PRLr carboxy-terminal tails precluded proliferation. In response to ligand, such complexes were incapable of activating-associated signaling pathways, as evidenced by a lack of Jak2 and Fyn activation and an absence of Sos phosphorylation. In comparison, replacement of any one of the carboxy-terminal tyrosines within the dimerized PRLr complex resulted in intermediate levels of ligand-induced signaling and proliferation. As seen in Fig. 3, however, replacement of these tyrosine residues either in trans or in cis resulted in either significantly diminished or absent PRLr function. These data demonstrate that the tyrosine residues at 309 and 382, as well as additional residues within the carboxy terminus of the dimerized PRLr complex, contribute to PRL-driven signaling and proliferation. Furthermore, these findings would indicate that the PRLr, like the receptor tyrosine kinases, may utilize a transphosphorylation mechanism in the initial activation of signaling from the dimerized receptor complex.

\section{PRLr signaling in the immune system}

Proximal signaling-protein tyrosine kinases

As schematized in Fig. 4, the functions of the PRL/PRLr complex in the immune system are mediated by receptorassociated signaling proteins. Lacking intrinsic enzymatic activity, ligand-induced dimerization of the PRLr complex serves to activate these associated signaling cascades. Some of the most proximal kinases activated during PRLr signaling are members of the JAK and Src families of protein tyrosine kinases (PTK). The Jak family of PTKs include JAKs 1-3 and Tyk2 (Silvennoinen et al. 1993, Ihle \& Kerr 1995) and are associated with early transduction events in all members of the cytokine receptor superfamily. Receptor-associated JAK2 is activated rapidly (within $5 \mathrm{~min}$ ) after engagement of PRL by its receptor (DaSilva et al. 1994, Lebrun et al. 1994, Rui et al. 1994a,b). Use of somatic cell genetics has determined that one substrate for the activity of JAK family members is the Stat 
family of transcription factors (Darnell et al. 1994). PRLinduced tyrosine phosphorylation of Stat 5, resulting in Stat dimerization and nuclear translocation, has been demonstrated in lymphocytes (Gilmour \& Reich 1994). Stat 5 transactivation is required for transcription initiation for several cytokine/PRL-regulated gene products including interferon regulatory factor 1, cyclin B and histone $\mathrm{H} 3$ (Yu-Lee 1990, Clevenger et al. 1992). While the JAK-Stat pathway provides a necessary signal for programmed gene expression and cell differentiation in lymphoid tissues, recent data have indicated that this pathway is not necessary for cell proliferation or survival (Fujii et al. 1995, Quelle et al. 1996). Two other PRLr-associated pathways may provide additional signals for lymphocyte proliferation and survival. By phosphorylating the PRLr at carboxyterminal tyrosines, Jak2 may enable the association of the signaling adaptor protein SHC with the PRLr, which in turn activates the Shc/Grb2/Vav/Sos/Ras/Rac/Raf/ MEK/MAPK signaling cascade (Erwin et al. 1995). A second pathway which may mediate a PRLr-specific proliferative signal is that associated with the Src-family member $\mathrm{p} 62^{\mathrm{fyn}}$. Fyn is also activated rapidly after ligandinduced PRLr dimerization. As shown by this laboratory and others (Clevenger \& Medaglia 1994, Li et al. 1996), direct substrates for PRL-activated Fyn include the guanine-nucleotide exchange factors Sos and Vav, which serve to activate both Ras and Rac G-proteins. Acting as allosteric activators, both $\mathrm{R}$ as and Rac serve to activate kinase cascades that ultimately activate the dual specificity kinase MAPK and S6 kinase that can directly phosphorylate and activate numerous transcription factors, such as Jun, Fos, p62, etc. While at face value the Jak/Stat and $\mathrm{Shc} / \mathrm{Grb} 2 / \mathrm{Vav} / \mathrm{Sos} / \mathrm{Ras} / \mathrm{Rac} / \mathrm{Raf} / \mathrm{MEK} / \mathrm{MAPK}$ pathways may appear as linear cascades, multiple interactions between the signaling complexes associated with the PRLr may occur. Indeed, the documented interactions between Fyn-Vav, Jak-Fyn, Grb2-Vav, and JAK2-Raf indicate the generation of proximal receptor-based signals occurs as the result of associated multimeric transduction complexes (Xia et al. 1996, Wang et al. 1997).

\section{Mediators of PRL-induced lymphocyte proliferation - Vav}

The structure of Vav is complex, and has multiple domains of potential functional significance identified on the basis of structural homology (Katzav et al. 1989, 1991, Adams et al. 1992, Feig 1994)). In its amino terminus, two domains with homology to a helix-loop-helix-like motif and a leucine zipper domain have been identified; these domains may serve to facilitate the interaction of Vav with other proteins and suppress an intrinsic transforming capability of this protein. Centrally located within Vav are two nuclear localization motifs, a cysteine-rich diacylglyceride (DAG) binding site, and a Dbl-GEF motif. The presence of a Dbl-GEF motif suggested that Vav may serve as a guanine nucleotide exchange factor (GEF) to the cytoskeleton-associated GTP binding protein Rho/Rac and contribute to cytoskeleton organization. Indeed recent data have shown Vav can function as a GEF for Rac-1 in vitro and in vivo, leading to activation of the JNK/Jun signal transduction pathway (Crespo et al. 1997). Some data, however, indicate that Vav may also associate and/or activate Ras GEFs during activation of the T-cell receptor and immunoglobulin (Gulbins et al. 1993, 1994c, Clevenger et al. 1995b). Finally, in the carboxy terminus of Vav reside two $\mathrm{SH} 2$ and one $\mathrm{SH} 3$ domains, with striking overall homology to the signal transduction adaptor protein Grb-2.

The presence of several structural domains within Vav would suggest that this molecule may participate in more than one signal transduction function. Vav is widely expressed in the mature lymphoid, myeloid, and erythroid lineages, and selectively in their differentiating precursors (Katzav et al. 1989, 1993, Coppola et al. 1991, Bustelo et al. 1992, 1993, Katzav 1993). Marked variations in the expression of Vav mRNA and protein were observed in developing thymic T-lymphocyte populations (Bustelo et al. 1993), suggesting that the regulation of this protein may be important during the development and expansion of $\mathrm{T}$ cells. The phosphorylation of Vav has been observed after stimulation of the T-cell receptor (Gulbins et al. 1993), membrane immunoglobulin (Gulbins et al. 1994c), Fc receptor (Margolis et al. 1992), interferon $\alpha$ receptor (Platanias \& Sweet 1994), c-kit (Alai et al. 1992), PRLr (Clevenger et al. 1995b), and the receptors for IL-1 (Gulbins et al. 1994a) and -2 (Evans et al. 1993). Antisense experiments have revealed that the inhibition of Vav expression in embryonic stem cells prevents their in vitro differentiation into mature hematopoietic elements (Wulf et al. 1993). These findings, however, have been contradicted in a recent study using vav $^{-1-}$ mouse embryonic stem cells (Zhang et al. 1994), as normal hematopoietic differentiation was observed in this system in vitro. Study of this knock-out in vivo in chimeric mice, however, has revealed decreased numbers of circulating $\mathrm{T}$ and $\mathrm{B}$ cells and impaired receptor-mediated signal transduction (Zhang et al. 1995). Thus, although these data question the role of Vav during embryonic hematopoiesis, they support its role as an important signaling factor involved in the immune response. Stimulation of both the T-cell receptor and PRLr in T-cell lines and surface immunoglobulin in B cells stimulates Vav-associated GEF activity (Gulbins et al. 1993, Clevenger et al. 1995b). Taken together, these data indicate that Vav expression contributes to immune system function, mediating critical growth and differentiation signals from ligand-stimulated hematopoietic receptors.

A GEF activity associated with Vav has been demonstrated during stimulation of the T-cell receptor (Gulbins et al. 1993) and membrane immunoglobulin (Gulbins et al. 1994c). This activity appeared to be regulated by PTKs (Gulbins et al. 1993), and by phorbol esters and DAG 
(Gulbins et al. 1994a,b). Regulation of Vav function by DAG was not unanticipated, given the presence of a cysteine-rich DAG-binding domain that is necessary for the transforming potential of oncogenic Vav (Coppola et al. 1991). The SH2 domain in Vav appears necessary for its interaction with the signaling adaptor proteins GRB2 and Shc in the Jurkat cell line (Ramos-Morales et al. 1994). Indeed, screening of phosphopeptide libraries indicates a preferential interaction of Vav's $\mathrm{SH} 2$ domain with the amino acid sequence phospho-Tyr-Met-Glu-Pro (Songyang et al. 1994). Mutations within this domain have been found to ablate oncogenic Vav's transforming potential (Katzav 1993), suggesting that protein-protein interactions are necessary for this potential. Vav contains an intrinsic oncogenic potential; removal or mutation within its amino-terminal helix-loop-helix-like domain produces a protein with potent transforming capabilities (Katzav et al. 1989, 1991, Coppola et al. 1991). Indeed, the oncogenic form of Vav was discovered before its normal protooncogenic counterpart, through the screening of esophageal carcinoma genomic DNA for transforming potential (Katzav et al. 1989). These data again suggest that proteinprotein interactions directed by the structural domains within Vav may critically regulate its signaling functions.

Indeed, this point is critical in understanding the role of Vav in PRLr signaling. While anti-sense ablation of Vav inhibits prolactin-induced proliferation in $\mathrm{Nb} 2$ cells (Clevenger et al. 1995b), other preliminary experiments in our laboratory have shown a direct interaction between the PRLr and Vav, as well as a possible downstream role for $\mathrm{Vav}$ in gene expression or regulation. To identify regions within the PRLr intracellular domain necessary for Vav interaction, human PRLr deletion mutants were expressed and purified as glutathione-S-transferase (GST) fusion proteins and analyzed for their capacity to bind Vav from $\mathrm{Nb} 2$ lysates as well as recombinant Vav. PRLr residues 323 to 527 were found necessary for in vitro association with both wild-type and recombinant forms of Vav. Interestingly, this region is deleted in the $\mathrm{Nb} 2$ form of the PRLr and suggests the PRL-induced proliferation of $\mathrm{Nb} 2$ cells may result from aberrant activation or altered ternary complex formation.

Following PRL stimulation of $\mathrm{Nb} 2$ cells, it was also found that Vav transiently translocates to the nucleus (Clevenger et al. 1995b). Within the nucleus, Vav could interact with several proteins via its leucine-rich, acidrich, SH2 and SH3 domains. It has been recently found that Vav can interact with heterogenous ribonucleoprotein $\mathrm{K}$ in vitro and in vivo (Hobert et al. 1994), and the putative transcriptional regulator ENX-1 (Hobert et al. 1996). Although the significance of these interactions is currently unknown, such a connection between these proteins may represent novel mechanisms regulating gene expression. Thus, through its interaction with both receptors and transcription factors, Vav may function both at the cell membrane and within the nucleus.
Mediators of PRL-induced lymphocyte survival - Bag-1

While signaling through the above cascades provides a molecular framework for the immunoproliferative effects of PRL, the biochemical basis for the anti-apoptotic effects of this hormone on lymphocyte progenitors has been largely uncharacterized. Recent studies have suggested that members of the Bcl-2 family, or associated proteins may regulate this phenomenon. In examining the PRL-dependent pro- $\mathrm{T}$ cell line Nb2, Buckley and his colleagues have demonstrated a significant modulation in the RNA levels of both Bcl-2 and Bax in response to PRL (Leff et al. 1996), while more modest changes were noted at the protein level. Given similar findings by our laboratory (Clevenger et al. 1997), we have recently focused our attention on the Bcl-2-associated protein Bag-1 (for Bcl-2-associated anti-death gene 1). Bag-1 encodes for a 219 amino acid protein, which migrates in SDS-PAGE at $29 \mathrm{kDa}$ (Takayama et al. 1995). When co-expressed with Bcl-2 in Jurkat cells, a significant increase in resistance to cell death triggered by treatment with anti-Fas antibody or staurosporine was observed (Takayama et al. 1995). Our findings revealed that removal of ligand from the PRL-dependent rat T-cell line $\mathrm{Nb} 2$, or the IL-3-dependent murine pro-B cell line $\mathrm{Ba} / \mathrm{F} 3$, induced significant decreases in the overall Bag-1 protein levels before the earliest detectable evidence for cellular apoptosis (Clevenger et al. 1997). Similarly, Dex treatment of the $\mathrm{Nb} 2$ line lead to dramatic decreases in overall Bag-1 levels, again before the onset of Dexinduced apoptosis. Exposure of Dex-treated $\mathrm{Nb} 2$ cells to PRL inhibited apoptosis $(10-20 \%$ cell death in cells treated with PRL and Dex, vs $>90 \%$ cell death in Dex-treated cells); examination of lysates from these cultures by anti-Bag-1 immunoblot analysis found intermediate levels of cellular Bag-1. Further corroboration of these findings was obtained by the study of SFJCD1 cells. SFJCD1 represents a spontaneous subline of $\mathrm{Nb} 2$ which is both PRL-independent and Dex-resistant, unlike the parental $\mathrm{Nb} 2$ cells. Examination of the SFJCD1 subline during Dex treatment or PRL withdrawal found constitutively high levels of Bag-1 in cells whose viability remained high, despite such treatments. To confirm that the regulation of Bag-1 levels directly contributed to cellular resistance to apoptosis, the IL-3-dependent Ba/F3 line was transfected with a Bag-1 expression construct. Overexpression of Bag- 1 in $\mathrm{Ba} / \mathrm{F} 3$ rendered the transfectants completely growth factor independent. The cellular survival of both IL-2-dependent cell lines and mitogenstimulated normal peripheral blood lymphocytes also appears to be regulated by Bag-1 levels (Adachi et al. 1996). These findings collectively demonstrate that Bag-1 protein levels are intimately linked to the survival of cytokine-dependent lymphoid lines and normal lymphocytes, and that the enhanced expression of Bag-1 promotes lymphocyte survival. 
Initial in vitro studies indicated that Bag-1 could interact with $\mathrm{Bcl}-2$, and could potentiate the effects of $\mathrm{Bcl}-2$ in vivo (Takayama et al. 1995). Previous data had suggested that Bcl-2 could weakly interact with the p72-74 kDa serine/ threonine kinase Raf-1. Although no evidence has been found for a direct phosphorylation of Bcl-2 by Raf-1, the synergy between these molecules in inhibiting apoptosis when co-transfected (Wang et al. 1994), suggested that other molecules could contribute to their interaction. Indeed, when tested by two separate laboratories, Bag-1 interacted both in vitro (i.e. recombinant-recombinant protein) and in vivo (i.e. by co-immunoprecipitation, and yeast two-hybrid screening) with both Raf-1 and Bcl-2 (Wang et al. 1996, Olivier et al. 1997). The Bag-1-Raf interaction may lead to a modest increase in the overall level of kinase activity of Raf-1, as found when both proteins are overexpressed in human 293 or insect Sf9 cells (Wang et al. 1996). These studies have demonstrated that the Bag-1-Raf interaction is mediated by the carboxy termini of both molecules. Bag-1 also appears capable of forming complexes with heat shock proteins (Zeiner \& Gehring 1995, S Takayama, S Krajewski, M Krajewski, S Kitada, JM Zapata, K Kochel, D Knee, GJ Miller, D Scudiero, G Tudor, EA Sausville \& JC Reed, unpublished observations) in the presence of ATP. Thus, while the potential effector molecules for Bag-1 function have been identified, the precise mechanisms through which Bag-1 affects these functions remains a fertile area of future investigation.

\section{Clinical applications and future directions}

Several lines of evidence suggest that the manipulation of PRL levels may have significant clinical utility. The increases in PRL levels in patients undergoing cardiac allograft rejection (Carrier et al. 1987), modulation of graft survival (Comsa et al. 1975), the decrease in immunoresponsiveness of humans receiving dopamine in the intensive care setting (Devins et al. 1992, Martinelli et al. 1996, Zellweger et al. 1996, Bailey \& Burchett 1997), and the association between increased PRL levels and severity of systemic lupus erythematosus (SLE) (McMurray et al. 1992, 1993) support the potential utility of pharmacotherapy aimed at the PRL/PRLr complex. Indeed, the treatment of SLE patients with bromocriptine appears to have some efficacy in improving the course of disease (McMurray et al. 1995). While the data obtained from these endocrine-targeted therapies (i.e. bromocriptine) appear encouraging, the development of advanced pharmacologic agents capable of blocking PRL/PRLr expression and/or action at both the endocrine and autocrine/paracrine levels may hold even greater promise.

While our knowledge of the relationship of PRL/PRLr to the immune system has advanced tremendously over the past 20 years, significant questions remain regarding both the physiologic and molecular mechanisms of action of this hormone complex. Specifically, little is known regarding the stimuli or the pathways that regulate the expression of both PRL and the PRLr in lymphocytes. The functional significance and the regulation of expression of the human PRLr isoforms has not been characterized. Finally, the effects of PRL on the expression and function of other cytokines and their receptors within the immune system remains to be determined. Further study of the mechanisms of the PRL/PRLr complex within the immune system may therefore provide crucial insights into the function and ultimate therapeutic potential of this receptor complex.

\section{Acknowledgements}

This work was funded in part by grants R29 AI33510, R01 DK50771 and R01 CA69294 from the National Institutes of Health to C V C. JB K is a recipient of National Research Service Award F32 DK09727 from the National Institutes of Health. C V C is also a recipient of a Junior Faculty Research Award JFRA-588 from the American Cancer Society.

\section{References}

Adachi M, Sekiya M, Torigoe T, Takayama S, Reed JC, Miyazaki T, Minami Y, Taniguchi T \& Imai K 1996 Interleukin-2 (IL-2) upregulates Bag-1 gene expression through serine-rich region within IL-2 receptor $\beta_{c}$ chain. Blood 88 4118-4123.

Adams JM, Houston H, Allen J, Lints T \& Harvey R 1992 The hematopoietically expressed vav proto-oncogene shares homology with the dbl GDP-GTP exchange factor, the bcr gene and a yeast gene (CDC24) involved in cytoskeletal organization. Oncogene 7 611-618.

Alai M, Mui ALF, Cutler RL, Bustelo XR, Barbacid M \& Krystal G 1992 Steel factor stimulates the tyrosine phosphorylation of the proto-oncogene product, $\mathrm{p} 95^{\text {vav }}$, in human hematopoietic cells. Journal of Biological Chemistry 267 18021-18025.

Ali S, Pellegrini I \& Kelly PA 1991 A prolactin-dependent immune cell line $(\mathrm{Nb} 2)$ expresses a mutant form of prolactin receptor. Journal of Biological Chemistry 266 20110-20117.

Ali S, Edery M, Pellegrini I, Lesueur L, Paly J, Djiane J \& Kelly PA $1992 \mathrm{The} \mathrm{Nb} 2$ form of prolactin receptor is able to activate a milk protein gene promoter. Molecular Endocrinology 6 1242-1248.

Bailey AR \& Burchett KR 1997 Effect of low-dose dopamine on serum concentrations of prolactin in critically ill patients. British Journal of Anaesthesia 78 97-99.

Bazan JF 1989 A novel family of growth factor receptors: a common binding domain in the growth hormone, prolactin, erythropoietin and IL-6 receptors, and the p75 IL-2 receptor beta-chain. Biochemical and Biophysical Research Communications 164 788-795.

Bazan JF 1990 Haematopoietic receptors and helical cytokines. Immunology Today 11 350-354.

Benedetto N, Folgore A, Galdiero M, Meli R \& DiCarol R 1995 Effect of prolactin, rIFN-gamma or rTNF-alpha in murine toxoplasmosis. Pathologie Biologie 43 395-400.

Berczi L, Nagy E, Kovacs K \& Horvath E 1981 Regulation of humoral immunity in rats by pituitary hormones. Acta Endocrinologica 98 506-513. 
Bernton EW, Meltzer MS \& Holaday JW 1988 Suppression of macrophage activation and T-lymphocyte function in hypoprolactinemic mice. Science 239 401-404.

Berwaer M, Martial JA \& Davis JRE 1994 Characterization of an up-stream promoter directing extrapituitary expression of the human prolactin gene. Molecular Endocrinology 8 635-642.

Boutin JM, Jolicoeur C, Okamura H, Gagnon J, Edery M, Shirota M, Banville D, Dusanter-Fourt I, Djiane J \& Kelly PA 1988 Cloning and expression of the rat prolactin receptor, a member of the growth hormone/prolactin receptor gene family. Cell $\mathbf{5 3}$ 69-77.

Boutin JM, Edery M, Shirota M, Jolicoeur C, Lesueur L, Ali S, Gould D, Djiane J \& Kelly P 1989 Identification of a cDNA encoding a long form of prolactin receptor in human hepatoma and breast cancer cells. Molecular Endocrinology 3 1455-1461.

Bustelo XR, Ledbetter JA \& Barbacid M 1992 Product of vav proto-oncogene defines a new class of tyrosine protein kinase substrates. Nature 356 68-71.

Bustelo XR, Rubin SD, Suen K-L, Carasco D \& Barbacid M 1993 Developmental expression of the vav protooncogene. Cell Growth and Differentiation 4 297-308.

Carrier M, Emery RW, Wild-Mobley J, Perotta NJ, Russell DH \& Copeland JG 1987 Prolactin as a marker of rejection in human heart transplantation. Transplantation Proceedings 29 3442-3443.

Chang W-P \& Clevenger CV 1996 Modulation of growth factor receptor function by isoform heterodimerization. Proceedings of the National Academy of Sciences of the USA 93 5947-5952.

Chang W-P, Ye Y \& Clevenger CV 1998 Stoichiometric structure/function analysis of the prolactin receptor signaling domains by receptor chimeras. Molecular and Cellular Biology 18 896-905.

Clevenger CV \& Medaglia MV 1994 The protein tyrosine kinase $\mathrm{p} 59^{\mathrm{fyn}}$ is associated with prolactin receptor and is activated by prolactin stimulation of T-lymphocytes. Molecular Endocrinology 8 674-681.

Clevenger CV \& Plank TL 1997 Prolactin as an autocrine/paracrine growth factor in breast tissue. Journal of Mammary Gland Biology and Neoplasia 2 59-68.

Clevenger CV, Russell DH, Appasamy PM \& Prystowsky MB 1990 Regulation of IL2-driven T-lymphocyte proliferation by prolactin. Proceedings of the National Academy of Sciences of the USA 87 6460-6464.

Clevenger CV, Altmann SW \& Prystowsky MB 1991 Requirement of nuclear prolactin for interleukin-2-stimulated proliferation of $\mathrm{T}$ lymphocytes. Science 253 77-79.

Clevenger CV, Sillman AL, Hanley-Hyde J \& Prystowsky MB 1992 Requirement for prolactin during cell cycle regulated gene expression in cloned T-lymphocytes. Endocrinology 130 3216-3222.

Clevenger CV, Chang W-P, Ngo W, Pasha TLM, Montone KT \& Tomaszewski JE 1995a Expression of prolactin and prolactin receptor in human breast carcinoma: Evidence for an autocrine/paracrine loop. American Journal of Pathology 146 1-11.

Clevenger CV, Ngo W, Sokol DL, Luger SM \& Gewirtz AM 1995 b Vav is necessary for prolactin-stimulated proliferation and is translocated into the nucleus of a T-cell line. Journal of Biological Chemistry 270 13246-13253.

Clevenger CV, Thickman K, Ngo W, Chang W-P, Takayama S \& Reed JC 1997 Role of Bag-1 in the survival and proliferation of the cytokine-dependent lymphocyte lines, Ba/F3 and $\mathrm{Nb} 2$. Molecular Endocrinology 11 608-618.

Comsa J, Leonhardt H \& Schwarz JA 1975 Influence of the thymus-corticotropin-growth hormone interaction on the rejection of skin allografts in the rat. Annals of the New York Academy of Sciences 249 387-401.

Coppola J, Bryant S, Koda T, Conway D \& Barbacid M 1991 Mechanism of activation of the vav protooncogene. Cell Growth and Differentiation 2 95-105.
Crespo P, Schuebel KE, Ostrom AA, Gutkind JS \& Bustelo XR 1997 Phosphotyrosine-dependent activation of Rac-1 GDP/GTP exchange by the vav proto-oncogene product. Nature 385 169-172.

Dardenne M, de Morales MCL, Kelly PA \& Gagnerault M-C 1994 Prolactin receptor expression in human hematopoietic tissues analyzed by flow cytofluorimetry. Endocrinology 134 2108-2114.

Darnell JE, Kerr IM \& Stark GR 1994 JAK-STAT pathways and transcriptional activation in response to IFNs and other extracellular signaling proteins. Science 264 1415-1421.

DaSilva L, Howard OMZ, Rui H, Kirken RA \& Farrar WL 1994 Growth signaling and JAK2 association mediated by membraneproximal cytoplasmic regions of prolactin receptors. Journal of Biological Chemistry 269 18267-18270.

Devins SS, Miller A, Herndon BL, O’Toole L \& Reisz G 1992 Effects of dopamine on T-lymphocyte proliferative response and serum prolactin concentrations in critically ill patients. Critical Care Medicine 20 1644-1649.

Di Carlo R, Meli R, Galdiero M, Nuzzo I, Bentivoglio C \& Carratelli CR 1993 Prolactin protection against lethal effects of Salmonella typhimurium. Life Sciences 53 981-989.

DiMattia GE, Gellersen B, Bohnet HG \& Friesen HG 1986 A human B-lymphoblastoid cell line produces prolactin. Endocrinology 122 2508-2517.

Elberg G, Kelly PA, Djiane J, Binder L \& Gertler A 1990 Mitogenic and binding properties of monoclonal antibodies to the prolactin receptor in $\mathrm{Nb} 2$ rat lymphoma cells. Journal of Biological Chemistry 265 14770-14776.

Erwin RA, Kirken RA, Malbarba MG, Farrar WL \& Rui H 1995 Prolactin activates Ras via signaling proteins SHC, growth factor receptor bound 2, and son of sevenless. Endocrinology 136 3512-3518.

Evans GA, Howard OZM, Erwin R \& Farrar WL 1993 Interleukin-2 induces tyrosine phosphorylation of the vav proto-oncogene product in human T cells: lack of requirement for the tyrosine kinase lck. Biochemical Journal 294 339-342.

Evans-Storms RB \& Cidlowski JA 1995 Regulation of apoptosis by steroid hormones. Journal of Steroid Biochemistry and Molecular Biology 53 1-6.

Feig LA 1994 Guanine-nucleotide exchange factors: a family of positive regulators of Ras and related GTPases. Current Opinion in Cell Biology 6 204-211.

Fletcher-Chiappini SE, Comptom MM, Lavoie HA, Day EB \& Witorsch RJ 1993 Glucocorticoid-prolactin interactions in $\mathrm{Nb} 2$ lymphoma cells: Antiproliferative versus anticytolytic effects. Proceedings of the Society for Experimental Biology and Medicine 202 345-352.

Fujii H, Nakagawa Y, Schindler U, Kawahara A, Mori H, Bouilleux F, Groner B, Ihle JN, Minami Y, Miyazaki T \& Taniguchi T 1995 Activation of Stat 5 by interleukin 2 requires a carboxyl-terminal region of the interleukin 2 receptor $\beta$ chain but is not essential for the proliferative signal transmission. Proceedings of the National Academy of Sciences of the USA 92 5482-5486.

Gala RR 1991 Prolactin and growth hormone in the regulation of the immune system. Proceedings of the Society for Experimental Biology and Medicine 198 513-527.

Gellersen B, Kempf R, Telgmann R \& DiMattia GE 1994 Nonpituitary human prolactin gene transcription is independent of pit-1 and differentially controlled in lymphocytes and in endometrial stoma. Molecular Endocrinology 8 356-373.

Gellersen B, Kempf R, Telgmann R \& DiMattia GE 1995 Pituitary-type transcription of the human prolactin gene in the absence of Pit-1. Molecular Endocrinology 9 887-901.

Gilmour KC \& Reich NC 1994 Receptor to nucleus signaling by prolactin and interleukin 2 via activation of latent DNA-binding factors. Proceedings of the National Academy of Sciences of the USA 91 6850-6854.

Ginsburg E \& Vonderhaar BK 1995 Prolactin synthesis and secretion by human breast cancer cells. Cancer Research 55 2591-2595. 
Glick B 1984 Interrelation of the avian immune and neuroendocrine systems. Journal of Experimental Zoology 232 671-682.

Gulbins E, Coggeshall KM, Baier G, Katzav S, Burn P \& Altman A 1993 Tyrosine-kinase stimulated guanine nucleotide exchange activity of vav in T cell activation. Science 260 822-825.

Gulbins E, Coggeshall KM, Baier G, Telford D, Langlet C, Baier-Bitterlich G, Bonnefoy-Berard N, Burn P, Wittinghofer A \& Altman A 1994a Direct stimulation of vav guanine nucleotide exchange activity for ras by phorbol esters and diglycerides. Molecular and Cellular Biology 14 4749-4758.

Gulbins E, Coggeshall KM, Laglet C, Baier G, Bonnefoy-Berard N, Burn P, Wittinghoffer A, Katzav S \& Altman A $1994 b$ Activation of Ras in vitro and in intact fibroblasts by the vav guanine nucleotide exchange protein. Molecular and Cellular Biology 14 906-913.

Gulbins E, Langlet C, Baier G, Bonnefoy-Berard N, Herbert E, Altman A \& Coggeshall EM 1994c Tyrosine phosphorylation and activation of vav GTP/GDP exchange activity in antigen receptor-triggered B cells. Journal of Immunology 152 2123-2129.

Hartmann DP, Holoday JW \& Bernton EW 1989 Inhibition of lymphocyte proliferation by antibodies to prolactin. FASEB Journal 3 2194-2202. Hobert O, Jallal B, Schlessinger J \& Ullrich A 1994 Novel signaling pathway suggested by $\mathrm{SH} 3$ domain-mediated p95vav/heterogeneous ribonucleoprotein K interaction. Journal of Biological Chemistry 269 20225-20228.

Hobert O, Jallal B \& Ullrich A 1996 Interaction of Vav with ENX-1, a putative transcriptional regulator of homeobox gene expression. Molecular and Cellular Biology 16 3066-3073.

Horseman ND, Zhao W, Montecino-Rodriguiez E, Tanaka M, Nakashima K, Engle SJ, Smith F, Markoff E \& Dorshkind K 1997 Defective mammopoiesis, but normal hematopoiesis, in mice with a targeted disruption of the prolactin gene. EMBO Journal (In Press).

Ihle JN \& Kerr IM 1995 Jaks and Stats in signaling by the cytokine receptor superfamily. Trends in Genetics 11 69-74.

Kant GJ, Bauman RA, Anderson SM \& Mougey EH 1992 Effects of controllable vs uncontrollable chronic stress on stress-responsive plasma hormones. Physiology and Behavior 51 1285-1288.

Katzav S 1993 Single point mutations in the SH2 domain impair the transforming potential of vav and fail to activate proto-vav. Oncogene 8 1757-1763.

Katzav S, Martin-Zanca D \& Barbacid M 1989 Vav, a novel human oncogene derived from a locus ubiquitously expressed in hematopoietic cells. EMBO Journal 8 2283-2290.

Katzav S, Cleveland JL, Heslop HE \& Pulido D 1991 Loss of the amino-terminal helix-loop-helix domain of the vav proto-oncogene activates its transforming potential. Molecular and Cellular Biology 11 1912-1920.

Kenner JR, Holaday JW, Bernton EW \& Smith PF 1991 Prolactin-like protein in murine splenocytes: Morphologic and biochemical evidence. Progress in Neuroendocrinoimmunology $\mathbf{3}$ 188-195.

Kooijman R, Hooghe-Peters EL \& Hooghe R 1996 Prolactin, growth hormone, and insulin-like growth factor-1 in the immune system. Advances in Immunology 63 377-454.

Lebrun JJ, Ali S, Sofer L, Ullrich A \& Kelly PA 1994 Prolactin-induced proliferation $\mathrm{Nb} 2$ cells involves tyrosine phosphorylation of the prolactin receptor and its associated tyrosine kinase JAK2. Journal of Biological Chemistry 269 14021-14026.

Leff MA, Buckley DJ, Krumenacker JS, Reed JC, Miyashita T \& Buckley AR 1996 Rapid modulation of the apoptosis regulatory genes, $b c l-2$ and $b a x$ by prolactin in rat $\mathrm{Nb} 2$ lymphoma cells. Endocrinology 137 5456-5462.

Lesueur L, Edery M, Ali S, Paly J, Kelly PA \& Djiane J 1991 Comparison of long and short forms of the prolactin receptor on prolactin-induced milk protein gene transcription. Proceedings of the National Academy of Sciences of the USA 88 824-828.

Li B-Q, Subleski M, Fusaki N, Yamamoto T, Copeland T, Princler GL, Kung H-F \& Kamata T 1996 Catalytic activity of the mouse guanine nucleotide exchanger mSOS is activated by Fyn tyrosine protein kinase and the T-cell antigen receptor in T-cells. Proceedings of the National Academy of Sciences of the USA 93 1001-1005.

McMurray R, Keisler D, Kanuckel K, Izui S \& Walker SE 1992 Prolactin influences autoimmune disease activity in the female b/w mouse. Journal of Immunology 147 3780-3787.

McMurray RW, Keisler D, Izui S \& Walker SE 1993 Effects of parturition, suckling, and pseudopregnancy on variables of disease activity in the $\mathrm{B} / \mathrm{W}$ mouse model of systemic lupus erythematosus. Journal of Rheumatology 20 1143-1151.

McMurray RW, Weidensaul D, Allen SH \& Walker SE 1995 Efficacy of bromocriptine in an open label therapeutic trial for systemic lupus erythematosus. Journal of Rheumatology 22 2084-2091.

Margolis B, Hu P, Katzav S, Li W, Oliver JM, Ullrich A, Weiss A \& Schlessinger J 1992 Tyrosine phosphorylation of vav protooncogene product containing $\mathrm{SH}-2$ domain and transcription factor motifs. Nature $35671-74$.

Martinelli GP, Lui H, Clarke WP, Heisenleder DJ \& Knight RJ 1996 Prolactin suppression enhances the effects of perioperative donor-specific blood transfusion on graft survival. Journal of Surgical Research 64 190-197.

Matera L, Cesano A, Bellone G \& Oberholtzer E 1992 Modulatory effect of prolactin on the resting and mitogen-induced activity of $T$, B and NK lymphocytes. Brain, Behavior and Immunity 6 409-417.

Mershon J, Sall W, Mitchner N \& Ben-Jonathan N 1995 Prolactin is a local growth factor in rat mammary tumors. Endocrinology 136 $3619-3623$

Miura O, Cleveland JL \& Ihle JN 1993 Inactivation of erythropoietin receptor function by point mutations in a region having homology with other cytokine receptors. Molecular Cell Biology 13 1788-1795.

Montogomery DW, Zukoski CF, Shah GN, Buckley AR, Pacholczyk T \& Russell DH 1987 Concanavalin A-stimulated murine splenocytes produce a factor with prolactin-like bioactivity and immunoreactivity. Biochemical and Biophysical Research Communications 145 692-698.

Nagano M \& Kelly PA 1994 Tissue distribution and regulation of rat prolactin receptor gene expression. Journal of Biological Chemistry 269 13337-13345.

Nagy E \& Berczi I 1991 Hypophysectomized rats depend on residual prolactin for survival. Endocrinology 128 2776-2784.

Nagy E, Berczi I, Wren GE, Asa SL \& Kovacs K 1983 Immunomodulation by bromocriptine. Immunopharmacology 6 231-243.

Nicoll CS 1974 Physiological actions of prolactin. Handbook of Physiology, edn 7, pp 253-291. Washington, DC: American Physiological Society.

Olivier R, Otter I, Monney L, Wartmann M \& Borner C 1997 Bcl-2 does not require Raf kinase activity for its death-protective function. Biochemical Journal 324 75-83.

O'Neal KD \& Yu-Lee L-Y 1994 Differential signal transduction of the short, $\mathrm{Nb} 2$, and long prolactin receptors. Journal of Biological Chemistry $26926076-26082$.

Ormandy CJ, Camus A, Barra J, Damotte D, Lucas B, Buteau H, Edery M, Brousse N, Babinet C, Binart N \& Kelly PA 1997 Null mutation of the prolactin receptor gene produces multiple reproductive defects in the mouse. Genes and Development $\mathbf{1 1}$ $167-178$.

Pellegrini I, Lebrun J-J, Ali S \& Kelly PA 1992 Expression of prolactin and its receptor in human lymphoid cells. Molecular Endocrinology 6 1023-1031.

Platanias LC \& Sweet MC 1994 Interferon $\alpha$ induces rapid tyrosine phosphorylation of the vav proto-oncogene product in hematopoietic cells. Journal of Biological Chemistry 269 3143-3146.

Prystowsky MB \& Clevenger CV 1994 Prolactin as a second messenger for interleukin 2. Immunomethods 5 49-55.

Quelle FW, Wang D, Nosaka T, Thierfelder WE, Stravopodis D, Weinstein Y \& Ihle JN 1996 Erythropoietin induces activation of 
Stat5 through association with specific tyrosines on the receptor that are not required for a mitogenic response. Molecular and Cellular Biology 16 1622-1631.

Ramos-Morales F, Druker BJ \& Fischer S 1994 Vav binds to several $\mathrm{SH} 2 / \mathrm{SH} 3$ containing proteins in activated lymphocytes. Oncogene 9 1917-1923.

Riddle O \& Braucher PF 1931 Studies on the physiology of reproduction in birds. XXX. Control of the special secretion of the crop-gland in pigeons by an anterior pituitary hormone. American Journal of Physiology 97 617-625.

Riddle O, Bates RW \& Dykshorn SW 1933 The preparation, identification and assay of prolactin - a hormone of the anterior pituitary. American Journal of Physiology 105 191-216.

Rui H, Kirken RA \& Farrar WL 1994a Activation of receptorassociated tyrosine kinase JAK2 by prolactin. Journal of Biological Chemistry 269 5364-5368.

Rui H, Lebrun J-J, Kirken RA, Kelly PA \& Farrar WL $1994 b$ JAK2 activation and cell proliferation induced by antibody-mediated prolactin receptor dimerization. Endocrinology 135 1299-1306.

Russell DH, Matrisian L, Kibler R, Larson DF, Poulos B \& Magun BE 1984 Prolactin receptors on human lymphocytes and their modulation by cyclosporine. Biochemical and Biophysical Research Communications 121 899-906.

Silvennoinen O, Witthuhn BA, Quelle FW, Cleveland JL, Yi T \& Ihle JN 1993 Structure of the murine Jak2 protein tyrosine-kinase and its role in interleukin 3 signal transduction. Proceedings of the National Academy of Sciences of the USA 90 8429-8433.

Skwarlo-Sonta K 1990 Mitogenic effect of prolactin on chicken lymphocytes in vitro. Immunology Letters 24 171-178.

Songyang Z, Shoelson SE, McGlade J, Olivier P, Pawson T, Bustelo XR, Barbacid M, Sabe H, Hanafusa H, Yi T, Ren R, Baltimore D, Ratnofsky S, Feldman RA \& Cantley LC 1994 Specific motifs recognized by the SH2 domains of Csk, 3BP2, pfs/fes, Grb2, HCP, Shc, Syk amd Vav. Molecular and Cellular Biology 14 2777-2785.

Takayama S, Sato T, Krajewski S, Kochei K, Irie S, Millan JA \& Reed JC 1995 Cloning and functional analysis of BAG-1: A novel Bcl-2-binding protein with anti-cell death activity. Cell $\mathbf{8 0}$ 279-284.

Telgmann R, Maronde E, Tasken K \& Gellersen B 1997 Activated protein kinase $\mathrm{A}$ is required for differentiation-dependent transcription of the decidual prolactin gene in human endometrial stromal cells. Endocrinology 138 929-937.

Wang H-G, Miyashita T, Takayama S, Sato T, Torigoe T, Krajewski S, Tanaka S, Hovey L, Troppmair J, Rapp U \& Reed JC 1994 Apoptosis regulation by interaction of $\mathrm{Bcl}-2$ protein and $\mathrm{Raf}-1$ kinase. Oncogene 9 2751-2756.
Wang H-G, Takayama S, Rapp UR \& Reed JC 1996 Bcl-2 interacting protein, Bag-1, binds to and activates the kinase Raf-1. Proceedings of the National Academy of Sciences of the USA $\mathbf{9 3}$ 7063-7068.

Wang X-J, Fuhrer DK, Marshall MS \& Yang U-C 1997 Interleukin-11 induces complex formation of Grb2, Fyn, and JAK2 in 3T3L1 cells. Journal of Biological Chemistry 270 27999-28002.

Witorsch RJ, Day EB, Lavoie HA, Hashemi N \& Taylor JK 1993 Comparison of glucocorticoid-induced effects in prolactin-dependent and autonomous rat $\mathrm{Nb} 2$ lymphoma cells. Proceedings of the Society for Experimental Biology and Medicine 203 454-460.

Wulf GM, Adra CN \& Lim B 1993 Inhibition of hematopoietic development from embryonic stem cells by antisense vav RNA. EMBO Journal 12 5065-5074.

Wyllie AH 1980 Glucocorticoid-induced thymocyte apoptosis is associated with endogenous endonuclease activation. Nature 284 $555-556$

Xia K, Mukhopadhyay NK, Inhorn RC, Barber DL, Rose PE, Lee RS, Narsimhan RP, D'Andrea AD, Griffen JD \& Roberts TM 1996 The cytokine-activated tyrosine kinase JAK2 activates Raf-2

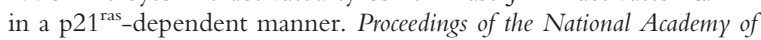
Sciences of the USA 93 11681-11686.

Yu-Lee L-Y 1990 Prolactin stimulates transcription of growth-related genes in $\mathrm{Nb} 2 \mathrm{~T}$ lymphoma cells. Molecular and Cellular Endocrinology 68 21-28.

Yu-Lee LY 1997 Molecular actions of prolactin in the immune system. Proceedings of the Society for Experimental Biology and Medicine $21535-52$.

Zeiner M \& Gehring U 1995 A protein that interacts with members of the nuclear hormone receptor family: Identification and cDNA cloning. Proceedings of the National Academy of Sciences of the USA 92 11465-11469.

Zellweger R, Wichman MW, Ayala A, DeMaso CM \& Chaudry IH 1996 Prolactin: A novel and safe immunomodulating hormone for the treatment of immunodepression following severe hemorrhage. Journal of Surgical Research 63 53-58.

Zhang R, Tsai F-Y \& Orkin SH 1994 Hematopoietic development of vav $\pm / \pm$ mouse embryonic stem cells. Proceedings of the National Academy of Sciences of the USA 91 12755-12759.

Zhang R, Alt FW, Davidson L, Orkin SH \& Swat W 1995 Defective Signalling through the $\mathrm{T}$ - and $\mathrm{B}$-cell antigen receptors in lymphoid cells lacking the vav proto-oncogene. Nature 374 470-473.

Received 23 October 1997

Accepted 11 December 1997 